\title{
EXPERIMENTAL INVESTIGATION OF BOND BETWEEN GFRP REINFORCEMENT AND CONCRETE USING PULL-OUT TEST
}

\author{
I. Hollý*, N. Gažovičová***
}

\begin{abstract}
Corrosion of steel reinforcement is the major cause of deterioration of existing RC structures. Glass fiber reinforcement polymer (GFRP) bars are suitable alternatives to steel bars in reinforced concrete applications. The bond between concrete and reinforcement is one of the basic requirements for the composite action of both materials. The transfer of forces between the steel reinforcement and the concrete is provided by the following mechanisms: adhesion, friction and mechanical interlocking. The bond between GFRP reinforcement and concrete is different and it is ensured by friction and mechanical interlocking of the rebar surface. The chemical bond does not originate between GFRP reinforcement and the surrounding concrete, so adhesion does not contribute to transfer of the bond forces. Some few test methods are used to determine the bond between GFRP reinforcement and concrete. The pull-out test were used to determine the bond behaviour between GFRP rebars and concrete. This paper describes the preparation, process, results and evaluation of the pull-out tests.
\end{abstract}

Keywords: concrete, GFRP reinforcement, bond, temperature, environmental conditions GFRP, bond behaviour, pull-out test

\section{Introduction}

In well designed and quality concrete have high alkalinity of the concrete pore solution. At this high $\mathrm{pH}$, the embedded reinforcing steel is protected against corrosion due to the formation of a submicroscopically thin film. (Karlsson, 2014) Real concrete structures are affected by environmental conditions. The environmental loads in time cause the degradation of concrete and reinforcement (Koteš et.al, 2016). Traditional material to reinforcing the concrete structures is steel. This material is protected against the corrosion by concrete alkalinity. The concrete carbonation, moisture, chlorides reduces the alkalinity of concrete. The use FRP as reinforcement in concrete structures is considered to be a possible alternative to steel in those situations where corrosion is present. In contrast to steel, there is yet no standardization for the surface characteristics of GFRP bars (Baena et al, 2009). The ensuring of the bond behaviour between GFRP reinforcement and concrete is fundamental requirement to design the concrete structures reinforced with these material. The form of the force transfer from concrete to reinforcement influences the construction behaviour - cracks width, distances between cracks, deflections, anchoring length and minimum thickness of the concrete cover. (Bilčík et al, 2015) The bond between GFRP reinforcement and concrete is ensured by friction and mechanical interlocking of the modified rebar surface. The force is transferred from the polymer matrix to fibres in GFRP. (McCallum, 2013).

The bond between GFRP and concrete is influenced by several factors: surface shape and mechanical properties of reinforcement (CNR-DT 203/2006) as well as rebar diameter, concrete compressive strength, anchoring length and confinement of reinforcement (Vilanova, 2015) Several test methods are used to determine the bond behaviour between reinforcement and concrete. For GFRP, two types of bond tests are used: pull-out tests and beam tests. The tests are different in the concept and they have also

Ing. Ivan Hollý, PhD.: Department of Concrete Structures and Bridges, Faculty of Civil Engineering SUT in Bratislava; Radlinskeho 11; 810 05, Bratislava; SK, ivan.holly@stuba.sk

** Ing. Natália Gažovičová.: Department of Concrete Structures and Bridges, Faculty of Civil Engineering SUT in Bratislava; Radlinskeho 11; 810 05, Bratislava; SK, natalia.gazovicova@stuba.sk 
different results. The bond stress obtained by the beam tests is usually less than the bond stress from the pull-out tests.The article shows the five pull-out tests results of one type of GFRP rebar. Samples were tested 3, respectively 28 days after their concreting.

\section{Experimental program}

\section{Materials}

The tensile tests of GFRP rebar with diameter $16 \mathrm{~mm}$ were also performed, the mean values are shown in Table 1. The concrete used for the pull-out specimens was prepared in the Central Laboratories Faculty of Civil Engineering Slovak University of Technology in Bratislava. The control samples (cubes and prisms) were cast to determine the concrete compressive strength and the modulus of elasticity of concrete. These tests were performed on the test day, so 3 days, respectively 28 days after concreting. The test samples have been manufactured and tests have been made according to the set of standards STN EN 12390. The test results are shown in Table 2.

Tab. 1: Geometric and mechanical properties of GFRP reinforcement

\begin{tabular}{ccc}
\hline Diameter $[\mathrm{mm}]$ & Tensile strength [MPa & Elastic modulus [GPa] \\
\hline 15.5 & 1069 & 54.7 \\
\hline
\end{tabular}

Tab. 2: Concrete specification

\begin{tabular}{ccc}
\hline Test day & Compressive cube strength [MPa & Modulus of elasticity [GPa] \\
\hline 3 & 19.83 & 37.8 \\
\hline 28 & 45.92 & 38.5 \\
\hline
\end{tabular}

\section{Experimental set-up and testing procedure}

The cube forms with $200 \mathrm{~mm}$ side were used as a mould for concreting of each concrete sample, see Fig. 1a. The bars were positioned vertical in the moulds. The GFRP reinforcement was separated from the concrete by a plastic pipe on the tension side. The bonded length of the GFRP reinforcement in concrete was $5 \varnothing$ (according the method by RILEM/CEB/FIB). The reinforcement separation has prevented the vault action on bond behaviour.

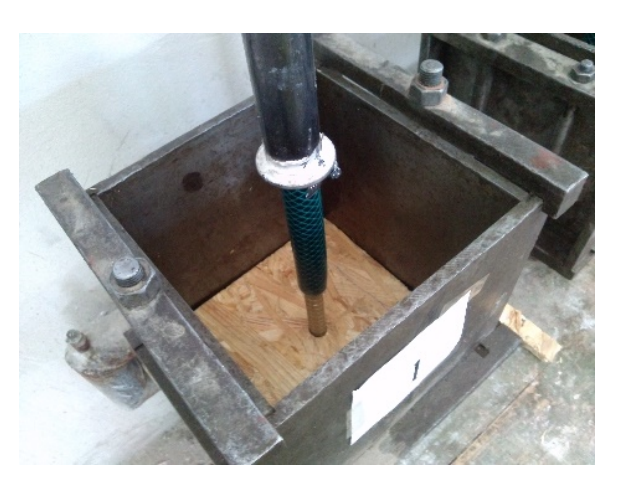

Fig. 1: a) Pull-out specimen.

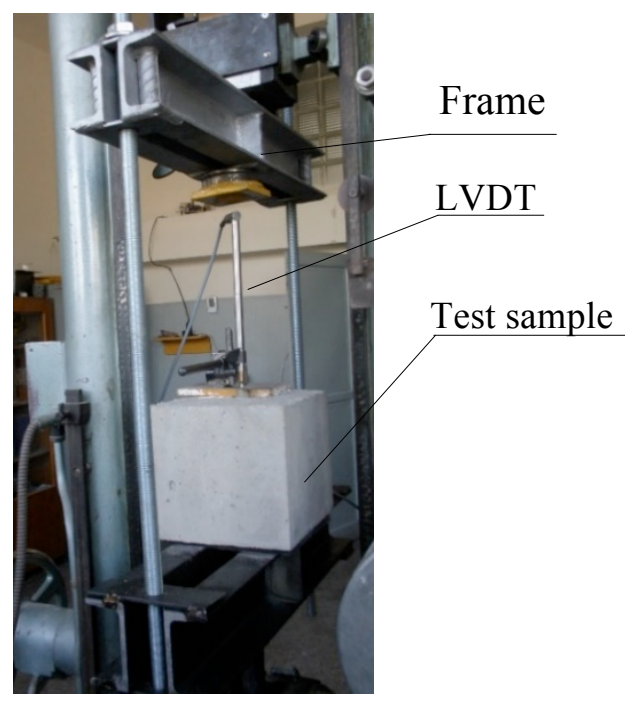

b) Pull-out test arrangement

The photo taken from the test is shown in Fig. 1b. The frame was made only to the pull-out test. The sample was positioned in a press machine with a load capacity of $100 \mathrm{kN}$. The slip of the bar at the unloaded end were measured with one LVDT. The pull-out load was applied to the specimen at a rate of $1.2 \mathrm{~mm} / \mathrm{min}$. 


\section{Results of pull-out test}

The bond stress is not constant over the whole rebar length. The average bond stress should be calculated according to Eq. 1 (ACI 440.3R-04):

$$
\tau_{b}=\frac{N}{\pi \cdot \phi \cdot l_{b}}
$$

where $\mathrm{N}$ is the tensile force, $\varnothing$ is the rebar diameter and $\mathrm{lb}$ is the bonded length. The results obtained from the experiment are shown in Table 3, where $\tau_{\max }$ is the maximally achieved bond stress, $s$ is the rebar slip at its unloaded end obtained from LVDT and $\sigma_{\mathrm{GFRP}}$ is the maximum tensile stress in reinforcement bars.

Tab. 3: The experimental results

\begin{tabular}{|c|c|c|c|c|c|}
\hline $\begin{array}{l}\text { Test } \\
\text { day }\end{array}$ & $\begin{array}{c}\text { Number of } \\
\text { sample }\end{array}$ & $\begin{array}{c}\tau_{\max } \\
{[\mathrm{MPa}]}\end{array}$ & $\begin{array}{c}\tau_{\max }{ }^{a} \\
{[\mathrm{MPa}]}\end{array}$ & $\begin{array}{c}\mathbf{s} \\
{[\mathrm{mm}]}\end{array}$ & $\sigma_{\mathrm{GFRP}}[\mathrm{MPa}]$ \\
\hline \multirow{2}{*}{3} & 1 & 11.992 & \multirow{2}{*}{11.79} & 1.072 & 232.3 \\
\hline & 2 & 11.589 & & 0.856 & 223.1 \\
\hline \multirow{3}{*}{28} & 1 & 15.356 & \multirow{3}{*}{15.308} & 3.587 & 297.5 \\
\hline & 2 & 15.286 & & 3.381 & 291.4 \\
\hline & 3 & 15.282 & & 3.084 & 293.5 \\
\hline
\end{tabular}

athe mean value for the same test sample

At the beginning of loading the bond between GFRP and concrete is ensured by mechanical interlocking of deformed surface rebar (Fig. 2). The slip at loaded end of the bar increases and the rebar deformations induce large interlocking. Thus originating microcracks at the tips of the bar are allowing the bar to slip. It is believed that the onset of the microcracks is delayed because of the softener surface deformations of the GFRP rebars when compared to that of steel bars. As the slip of the bar increases, the mechanical interlocking increase considerably. The radial component from the bond forces is balanced against the tensile hoop stresses in the surrounding concrete from concrete radial strain. As a consequence, the surrounding concrete exerts a confinement action on the bar. If the bar is not adequately confined and the value of the tensile hoop stresses exceeds the tensile strength of concrete, splitting cracks may be appear along the length of the rebar. These mode of bond failure did not appear in the test thanks to large concrete cover of the rebar. The second alternative is the use of heavy transverse reinforcement. The concrete splitting remains limited to a cracked core around the bar. If sufficient resistance to splitting can be provided, the bond stress can reach the maximum value. As both ends of the rebar are slipping, the bond stiffness decreases and the tensile load is transferred by friction (Fig. 2b).
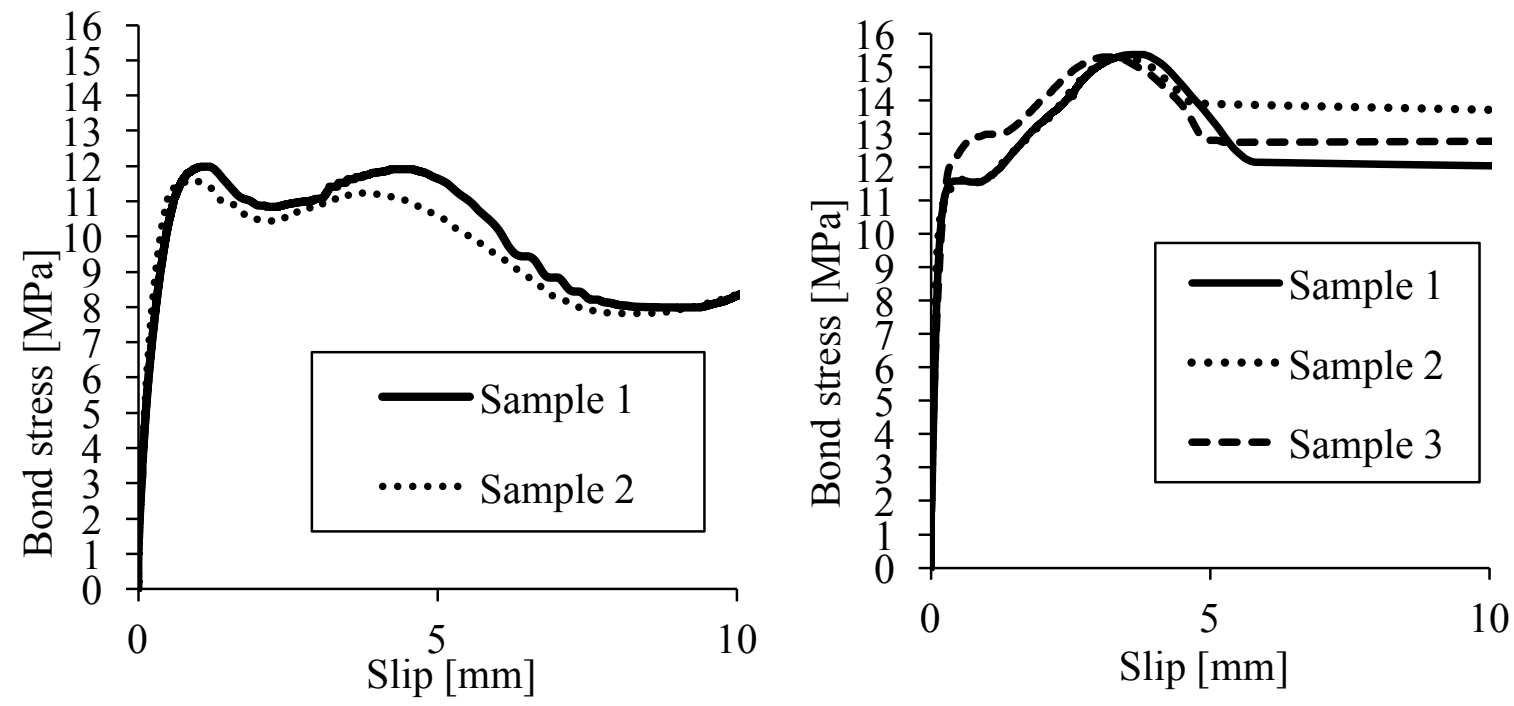

Fig. 2: Representative bond-slip curve after concreting: a) 3 days b) 28 days 
The test samples after bond failure are shown in Fig. 3. The bond failure occurred by shearing off part or all the surface deformations of the bar. At the time of testing 3 days after concreting, the young concrete did not provide a good confinement of the reinforcement which was demonstrated not only by a greater failure of the GFRP rebar surface but also by the absence of residual bond stress, see Fig. 2a and Fig. 3a.

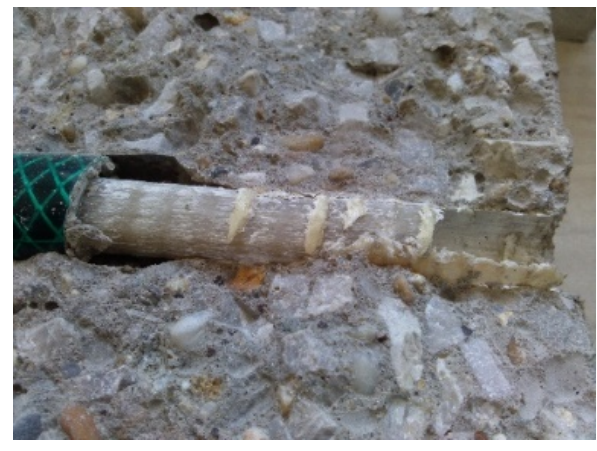

a)

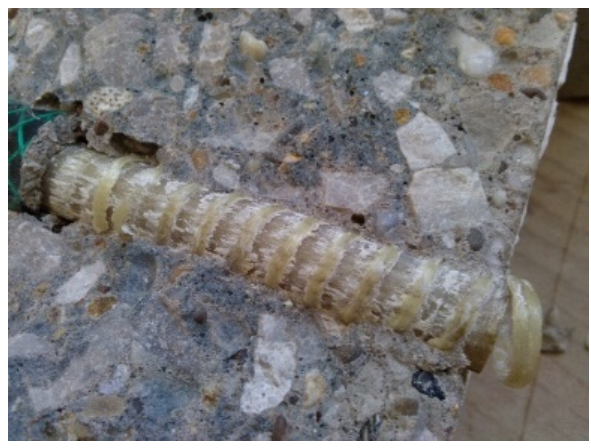

b)

Fig. 3: The test sample failure a) 3 days after concreting, b) 28 days after concreting

\section{Conclusions}

For GFRP an extensive experimental work is needed in order to develop reliable and rational guidelines for design. One property of importance that has been studied for many years is the bond between steel reinforcing bars and the concrete interface.The paper engages on the preparation, testing and evaluation of the pull-out tests GFRP rebars with concrete. Based on the test results, the following conclusions can be made:

- Bond between GFRP reinforcement and concrete depends on the shear strength between successive layers of fibre and bar deformations.

- The young concrete did not provide a good confinement of the reinforcement due to the amount of shrinkage. It influences the way of the reinforcement surface failure and the shape of the function between the bond stress and the slip of GFRP reinforcement.

\section{Acknowledgement}

This work was supported by the Slovak Research and Development Agency under the contract No. APVV-15-0658 and by University Science Park (USP) of the Slovak University of Technology in Bratislava (ITMS: 26240220084).

\section{References}

ACI 440.1R-06. (2006) Guide for the Design and Constr. of Structural Concrete Reinforced with FRP Bars p. 48. ACI 440.3R-04. Guide Test Methods for Fiber-Reinforced Polymers (FRPs) for Reinforcing or Strengthening

Baena Munoz, M.. (2010) Study of Bond Behaviour between FRP Reinforcement and Concrete: Diss. thesis, p. 340.

Baena, M., Torres, L., Turon, A. et al. (2009) Experimental study of bond behaviour between concrete and FRP bars using pull-out test, Composites Part B: Engineering, vol. 40, no. 8, pp. 784 - 797.

Bilčík, J., Gažovičová, N. and Hollý, I. (2015) Construction rules and principles, in: Manual for design of GFRP reinforcement, Bratislava, pp. 58 - 65.6 (in Slovak)

CNR-DT 203/2006. (2006) Guide for the Design and Construction of Concrete Structures Reinforced with FiberReinforced Polymer Bars, 2006, p. 39

Karlsson, J. (2014) Alternative Reinforcement Approaches - Extended service life of exposed concrete structures, Master's thesis, Chalmers University of Technology, Göteborg, Sweden

Koteš, P., Brodňan, M. and Bahleda, F. (2016) Diagnostics of Corrosion on a Real Bridge Structure. In: Advances in materials science and engineering. ISSN 1687-8434

McCallum, B. (2013) Experimental Evaluation of the Bond Dependent Coefficient and Parameters which Influence Crack Width in GFRP Reinforced Concrete: dissertation thesis, Halifax: Dalhousie University, p. 203.

Vilanova, M. (2015) Bond-Slip and Cracking Behaviour of Glass Fibre Reinforced Polymer Reinforced Concrete Tensile Members: dissertation thesis, p. 183. 